\title{
Relationship Between Perceived Social Support and Anxiety Before and After Cesarean in the Pregnant Women
}

\author{
Hashemi Zeinab* \\ Department of Midwifery, Iran
}

*Corresponding author: Hashemi Zeinab, Department of Midwifery, Lorestan University of Medical Sciences, Khorramabad, Iran

\section{ARTICLE INFO}

Received: 幽 February 18, 2021

Published: 慧 April 28, 2021

Citation: Hashemi Zeinab. Relationship Between Perceived Social Support and Anxiety Before and After Cesarean in the Pregnant Women. Biomed J Sci \& Tech Res 35(3)-2021. BJSTR. MS.ID.005698.

Keywords: Perceived Social Support; Anxiety; Cesarean

\begin{abstract}
Background \& Objective: Most pregnant women experience a degree of anxiety before and after cesarean. Anxiety can have unfavorable complications for the mother and the baby. Given the probable relationship of social support with the amount of anxiety, the present study aimed to determine the relationship between perceived social support and anxiety before and after cesarean in the pregnant women referring to Besat Hospital in Sanandaj in 2018.
\end{abstract}

Materials and Methods: This study was a descriptive-correlational and crosssectional study performed on 180 pregnant women under selective cesarean section surgery in 2018. Using the available sampling method, pregnant women referring to Besat Hospital in Sanandaj were selected with the criteria to enter the study. The data collection method in this study was a two-part questionnaire of demographic and midwifery information, perceived social support questionnaire and Dass 21 anxiety questionnaire. Data analysis was performed using SPSS software version 16, descriptive statistics, and the Pearson correlation test.

Result: Results indicated that the degree of the overall rate of anxiety before cesarean was $58.9 \%$ and in the post operation stage $19.5 \%$ respectively. In addition, there was a negative significant difference between social support and anxiety before the operation $(\mathrm{p}<0.05, \mathrm{r}=-0.633)$, and anxiety after cesarean $(\mathrm{P}<0.05, \mathrm{r}=-0.476)$.

Conclusion: The results of the study showed that there is a negative and significant relationship between perceived social support and anxiety before and after cesarean section. Hence it is advised that interventions be designed to identify and promote the level of social support in the pregnant women enrolled for Cesarean.

\section{Introduction}

Cesarean section means the exit of one or more newborns, or rarely, a dead fetus through the incision in the mother's abdominal wall and the uterus [1]. Caesarean section is one of the most common gynecological surgeries around the world [2]. However, it may cause mental and physical complications in the mother. Physical complications associated with cesarean section include intra- and postoperative bleeding, surgical site infections, intraabdominal adhesions, deep vein thrombosis (DVT) and pulmonary embolism [3]. Anxiety and stress are also considered psychological complications affecting mothers undergoing cesarean section [4].
Anxiety is a very unpleasant sensation that results from stress and appears in the form of severe fear or distress or suspicion for an unknown factor [5]. Anxiety causes symptoms such as hand and foot tremor, sweating, palpitations, nausea, diarrhea, dry mouth, decreased concentration and confusion [6]. The prevalence of preoperative anxiety varies from $11 \%$ to $80 \%$. Age, gender, culture, level of the individual's awareness of surgery, history of previous surgery, type and duration of surgery, and individual characteristics in stressful situations are some factors that can affect the level of anxiety suffered by patients [5]. 
Some of the main causes of preoperative anxiety include the fear of surgery, entering the unfamiliar environment, being away from the family, lack of knowledge and awareness about the way surgery is done and its possible consequences [7] waiting for surgery, fear of pain or nausea, waking up during surgery, or loss of control during surgery [8], concerns about post-surgical problems such as pain, discomfort, changes in body shape or functions, the possibility of increased dependence on others, and possible changes in lifestyle [9]. During the postoperative period, anxiety may increase as a result of sleep deprivation caused by the noise at the hospital, fatigue, and fear of failure to recover [10]. Anxiety results in difficulty in accessing the patient's veins increased the need for anesthetics, and also the increased chance of pain, nausea, and vomiting during the postoperative period [11]. Preoperative anxiety, if not controlled or prolonged, may result in reduced wound healing, increased risk of infection, and changes in sleep patterns, which can prolong hospitalization, the patient's delayed discharge, and increased care costs [12]. Pharmaceutical and nonpharmacological methods can be used to reduce the stress and anxiety induced by surgery [13].

Due to the sedative effects of pharmacological methods, the use of non- pharmacological interventions, especially in the cesarean section where close contact between the mother and the baby is important, is recommended [4]. On the other hand, mothers are often concerned about medicinal prescriptions because of their health or breastfeeding and thus seek alternative and complementary therapies [14]. Nonpharmacological methods include heat and cold therapy, hypnosis, music therapy, relaxation, aromatherapy, electrical stimulation of the nerves [15], and social support. Social support can play a very important role in reducing maternal stress and anxiety, and its importance in protecting the mother's health during pregnancy has been emphasized [16]. Social support means receiving health information, material and psychological assistance from favorite persons including a partner, a relative, a friend, or a social network such as health care providers [17]. Social support is classified into two subcategories of perceived and received support [18]. Perceived social support refers to the individual's estimation of the availability of support when it is needed. In fact, it refers to the perception that a person suffering from pain has access to effective people who are able to potentially help him when needed [19].

According to researchers, perceived social support is more important than received support for health behaviors. This conclusion is based on the argument that if sources of support are not perceived by a person, he/she will not use them [20]. The results of Bodaghi [21] study suggested that anxiety, depression, and stress in pregnant women have a negative relationship with social support [21]. However, Fayyazi, et al. [22] did not report a significant relationship between social support and anxiety in pregnant women [22]. Therefore, considering the complications of anxiety, the contradictory results regarding the relationship between perceived social support and anxiety, inadequate attention to the psychological complications of cesarean section and due to lack of knowledge in women undergoing cesarean section, this study aimed to determine the relationship between perceived social support and anxiety before and after cesarean section in pregnant women who referred to Besat Hospital in Sanandaj.

\section{Methodology}

This cross-sectional, descriptive-correlational study was conducted on 180 pregnant women referring to Besat Hospital in Sanandaj to undergo cesarean section. The inclusion criteria included pregnant women aged 18 to 45 years, fully alert, planned pregnancy, having a natural course of pregnancy, being healthy in terms of hearing and speech, lack of mental retardation in the mother, lack of history of infertility, lack of education in medicine.

and paramedics, lack of history of known mental illness, and other illnesses affecting the psychological state and surgical outcomes, not taking anti-anxiety and anti-stress drugs in the preoperative period, having no significant event other than pregnancy in the past 9 months, not having a disabled spouse or child, no history of cesarean section and previous surgery (non-cephalic view of the fetus, llacenta previa, two or multiple pregnancies,...) non-use of tobacco and drugs, and for the postcesarean section, in addition to the above, the birth of a seemingly healthy child was also an inclusion criterion. The exclusion criteria were the unwillingness to continue cooperation, tubectomy or hysterectomy during surgery, postpartum complications such as bleeding, eclampsia, fever and other postpartum complications, the death of the baby after birth, and the baby's hospitalization in the neonatal intensive care unit.

After obtaining permission from the Ethics Committee of Kurdistan University of Medical Sciences, the researcher recoursed for collecting information on consecutive days in the morning to the postpartum section of Besat Hospital and presented to pregnant women who were referred for preparation for cesarean section and had criteria for entering the study, provided an explanation of the purpose of the study. After signing the consent form, questionnaires for demographic and midwifery information, social support perception, and anxiety DASS 21 were completed by the participants in the pre-cesarean section 7 days after the cesarean. The demographic information questionnaire including questions about age, level of education, and occupation of the women and their husband, family income level, and midwifery characteristics such as questions about marital satisfaction, the level of parity and satisfaction with the baby's gender. To measure social support in this study, the Social Support Survey Scale (MOS-SSS)1 developed by Sherbourne, et al. [23] for use in medical outcomes, was administered to the respondents. 
The scale measures the respondents' social support using 19 statements and 5 sub-scales. These sub-scales include tangible support including material and behavioral support (items 9 to 12), emotional support that evaluates positive emotions, sympathy, and encouragement to express feelings (items 1-8), Information support that measures guidance, information or feedback (items 1- 8), kindness that measures love and affection (items 16 to 18), positive social interaction that measures the existence of individuals to engage in recreational activities (items 13, 14, 15, and 19). This scale is a self-report questionnaire that asks the participants to express the degree of their opposition or agreement with each of the statements based on a five-point Likert scale (never $=1$, rarely $=2$, sometimes $=3$ points, often $=4$, and always $=5$ points $]$. The lowest and the highest scores one may obtain on this scale are 19 and 95, respectively. To get the overall score, the sum of all scores is calculated. A higher score on this scale indicates that the person receives a higher level of social support. The reliability of this scale was reported using the Cronbach's alpha coefficient in the range of $74 \%$ to $93 \%$ [23].

Temanaifar, et al. [24] confirmed the face and content validity of the scale from the point of view of psychologists and estimated its reliability through the Cronbach's alpha coefficient as equal to 97\% [24]. Then, based on their perceived social support scores, the respondents were placed into three groups (low social support: scores 19 to 44), (average social support: scores 44 to 69), and (high social support: scores: 69 to 95: high social support) [25]. To assess the respondents' anxiety, the Depression, Anxiety, and Stress Scale (DASS 21) was administered. The scale consists of 21 items that measure depression, stress and anxiety, each by 7 items. The final score of each of the three scales is calculated as the sum of scores gained on that scale. The respondents' anxiety levels were assessed using items $2,4,7,9,15$, and 20 . The questions in this questionnaire are based on Likert and have four chances at all (none $=0$, low $=1$, average $=2$, and high $=3$ ). After calculating the sum of the scores of the seven items, the final score obtained on the anxiety subscale was multiplied by 2 in order to match the 42 -item scale. The final score obtained shows the severity of the symptoms (0-7: normal anxiety, 8-9: low anxiety, 10-14: average anxiety, 1519: severe anxiety, and $\leq 20$ : very severe anxiety). The reliability and validity of the scale have been confirmed in various studies in Iran [26] and abroad [27]. After completing the DASS 21in the pre-cesarean phase, the respondents completed the scale again 7 days after cesarean section. The collected data were analyzed using descriptive statistics and Pearson correlation test using SPSS software (version 16).

\section{Results}

The mean age of the respondents was $30.51 \pm 6.32$ and that of their husbands was $34.87 \pm 6.78$. Most of the respondents $(85.6 \%)$ were housewives and $92.8 \%$ of their husbands were employed. $73.3 \%$ of them had a sufficient level of income and the majority of the respondents and their husbands held a high school diploma (37\%). Most of the respondents (86.7\%) were satisfied with their marital life. Besides, the majority of the respondents (83.9\%) were satisfied with their baby's gender. Table 1 shows the frequency and level of perceived social support in the respondents. As it can be seen, the percentage of perceived social support in the majority of respondents (63.3\%) is within the score range of 44-69, indicating an average social support level.

Table 1: The frequency and level of perceived social support.

\begin{tabular}{|c|c|c|c|}
\hline Variable & Level & Frequency & Percentage \\
\hline & $19-44$ & 4 & $2.2 \%$ \\
\hline Perceived & $44-69$ & 114 & $63.3 \%$ \\
\hline Social Support & $69-95$ & 62 & 34.5 \\
\hline & Total & 180 & 100 \\
\hline
\end{tabular}

Also, 2.2\% of the research units had a low level and $34.5 \%$ had a high level of social support. Table 2 shows the respondents' levels of anxiety before and after cesarean section. As it is shown, the anxiety level in the majority of respondents before the cesarean section $(41.1 \%)$ and after cesarean section $(80.5 \%)$ is within the ange of $0-7$, indicating a normal level of anxiety.

Table 2: The respondents' levels of anxiety before and after cesarean section.

\begin{tabular}{|c|c|c|c|}
\hline Variable & Level & Frequency & Percentage \\
\hline & $0-7$ & 74 & $41.1 \%$ \\
\hline \multirow{2}{*}{$\begin{array}{c}\text { Anxiety before cesarean } \\
\text { section }\end{array}$} & $10-14$ & 53 & $17.8 \%$ \\
\hline & $15-19$ & 13 & $29.4 \%$ \\
\hline & $\leq 20$ & 8 & $7.3 \%$ \\
\hline & Total & 180 & $100 \%$ \\
\hline & $0-7$ & 145 & $80.5 \%$ \\
\hline & $10-14$ & 14 & $7.8 \%$ \\
\hline Anxiety after cesarean & $15-19$ & 2 & $10.6 \%$ \\
\hline section & $\leq 20$ & 0 & $1.1 \%$ \\
\hline & Total & 180 & $100 \%$ \\
\hline
\end{tabular}

The overall anxiety levels before and after the cesarean sections were $58.9 \%$ and $19.4 \%$, respectively. Table 3 shows the correlation between perceived social support and anxiety before and after cesarean section. The results of the Pearson correlation test showed a significant negative correlation between perceived social support and anxiety before and after cesarean section ( $\mathrm{p}$-value = 0.0001). The correlation coefficient values indicate the intensity and direction of this relationship. According to the obtained values, there a negative and strong correlation between the two variables, indicating that by increasing the level of perceived social support, the level of anxiety decreased before and after cesarean section. 
Table 3: Correlation between perceived social support and anxiety before and after cesarean section.

\begin{tabular}{|c|c|c|c|c|}
\hline \multicolumn{3}{|c|}{ Anxiety Before } & \multirow{2}{*}{$\begin{array}{c}\text { Anxiety After } \\
\text { cesarean }\end{array}$} & \multirow{2}{*}{$\begin{array}{c}\text { Perceived } \\
\text { social support }\end{array}$} \\
\hline Variable & Statistics & cesarean & & \\
\hline & & section & section & \\
\hline Perceived social & Correlation & -0.633 & -0.476 & 1 \\
\hline support & P-value & 0.0001 & 0.0001 & -------- \\
\hline Anxiety before & Correlation & 1 & 0.503 & -0.633 \\
\hline cesarean section & P-value & ----- & 0.0001 & 0.0001 \\
\hline Anxiety after & Correlation & 0.503 & 1 & -0.476 \\
\hline cesarean section & P-value & 0.0001 & ------- & 0.0001 \\
\hline
\end{tabular}

\section{Discussion}

The results of the study showed that the majority of the respondents experienced an average level of perceived social support. These results are consistent with a study conducted by Faramarzi, et al. [28] who reported the average social support among pregnant women [28], but contrary to the results of a study by Sadeghi Avalshahr et al., who reported high social support among mother [20]. The reason for the inconsistency between the two studies can be due to differences in the studied populations. The participants in Sadeghi et al.'s study were primiparous women, and such women are more likely to be supported by their relatives. The anxiety level of the respondents before the cesarean section was 58.9\% (17.8\% low anxiety, $29.4 \%$ average anxiety, $7.7 \%$ severe anxiety, and $4.4 \%$ very severe anxiety) and after cesarean section was $19.4 \%$ (7.8\% low anxiety, $10.6 \%$ average anxiety, and $1.1 \%$ severe anxiety). The results are consistent with the results of a study by Almalki, et al. [29] who reported a high level of anxiety in patients before elective surgery [29]. The findings of the present study showed a significant negative relationship between perceived social support and anxiety before and after cesarean section ( $p$ $<0.05)$.

This finding is consistent with the results of previous studies $[21,30]$. Social support is a protective factor against depression and anxiety in pregnant women, which, improves mental health through psychological mechanisms or the endocrine system. Social support in women is associated with positive mood, self-efficacy, self-esteem, proper self-esteem, good quality of life, and positive interpersonal relations [21]. When a person comes to believe that there are those who can help her when needed, her ability to overcome psychological pressures increases. In fact, perceived social support plays a moderating role in stressful life situations and has a positive role in the physical and psychological health of individuals [31]. Perceived social support can help a person who needs effective psychological help to cope with the pressures and problems of life because such a person has a clear perception in all the moment in life that there are some who help him/her when needed. Therefore, he/she stands more powerfully against difficulties [19]. The limitations of this study include the crosssectional nature of the study, the limited access to Besat Hospital, the relatively low number of respondents (despite the calculation of the sample size based on previous studies), the use of availability sampling technique and the possibility that the respondents' may have not provided honest responses in the presence of the researcher.

\section{Conclusion}

Considering the prevalence of anxiety before and after cesarean section, special attention needs to be paid to maintaining and improving the mental health of pregnant women, along with their physical health. Given the multiple complications of anxiety on mothers and infants and the relationship between social support and anxiety in the pre and postcesarean section, health managers and health care practitioners are recommended to design some interventions to identify and promote the level of social support for pregnant women who are volunteers for cesarean section. Mental health and its related factors in pregnant women and patients undergoing surgical procedures should be placed on the top of the research list of the university.

\section{Research Limitations}

The limitations of this study are that this study was a crosssectional study and there was the probability of not answering the research samples honestly to the questionnaire questions by the participants.

\section{Acknowledgments}

This paper is based on a master's thesis conducted at Kurdistan University of Medical Sciences. Therefore, we sincerely appreciate all officials of Kurdistan University of Medical Sciences, the staff of Besat Hospital in Sanandaj, all pregnant mothers who patiently answered the questionnaires, and all those who helped us in this study. (Code of Ethics IR.MUK.REC.1397.029). 


\section{References}

1. Petrou S, Khan K (2013) An overview of the health economic implications of elective caesarean section. Applied health economics and health policy 11(6): 561-576.

2. Chaudhary R, Raut KB, Pradhan K (2018) Prevalence and Indications of Cesarean Section in a Community Hospital of Western Region of Nepal. Journal of the Nepal Medical Association 56(213): 871-874.

3. Gass C (2006) It is the right of every anaesthetist to refuse to participate in a maternalrequest caesarean section. International journal of obstetric anesthesia 15(1): 33-35.

4. Kushnir J, Friedman A, Ehrenfeld M, Kushnir T (2012) Coping with preoperative anxiety in cesarean section: physiological, cognitive, and emotional effects of listening to favorite music. Birth 39(2): 121-127.

5. Bansal T, Joon A (2019) A comparative study to assess preoperative anxiety in obstetric patients undergoing elective or emergency cesarean section. Anaesthesia, Pain \& Intensive Care pp. 25-30.

6. Ajorpaz NM, Ezadi A, Heidari S (2014) Comparison of routine education and video CD on anxiety level before general surgery. Qom University of Medical Sciences Journal 8(5).

7. Dehghani H, Dehghani K, Nasiriani K, Banaderakhshan H (2013) The effect of familiarization with cardiac surgery process on the anxiety of patients undergoing coronary artery bypass graft surgery. JMC 10(4): 257-263.

8. LN Ebirim, Tobin M (2010) Factors responsible for pre-operative anxiety in elective surgical patients at a university teaching hospital: a pilot study. jioA 29(2): 1-6.

9. Babashahi M, Babashahi F, Fayazi S (2012) Comparing the effect of massage Aromatherapy and massage on anxiety level of the patients in the preoperative period: a clinical trial. Evidence Based Care 2(2): 19-28.

10. Comeaux T, Steele Moses S (2013) The effect of complementary music therapy on the patient's postoperative state anxiety, pain control, and environmental noise satisfaction. Medsurg nursing 22(5): 313-319.

11. Nigussie S, Belachew T, Wolancho W (2014) Predictors of preoperative anxiety among surgical patients in Jimma University specialized teaching hospital, South Western Ethiopia. BMC surgery 14(67): 1-10.

12. Saleh Moghaddam A, Mazloum SR, Zoka A (2016) The effect of Eeducational vidos on preoperation anxity among patients before undergoing open heart surgery without PUMP. The J Urmia Nurs Midwifery Fac 14(7): 648-657.

13. Palese A, Cecconi M, Moreale R, Skrap M (2012) Pre-operative stress, anxiety. depression and coping strategies adopted by patients experiencing their first or recurrent brain neoplasm: an explorative study. Stress and Health 28(5): 416-425.

14. Sharifipour F, Bakhteh A, Mirmohammad A (2015) Effects of citrus aurantium aroma on post-cesarean anxiety. Iranina Journal of Obstetrics Gynecology and Infertility 169: 12-20.

15. Ebrahimi Houshyar A, Hosein Rezaie H, Jahani Y, Kazemi M, Monfared S et al. (2015) Comparison of two methods of aromatherapy with lavender essence and Transcutaneous Electrical Nerve Stimulation (TENS) on cesarean postoperative pain. The Iranian Journal of Obstetrics, Gynecology and Infertility 18(146): 6-12.

16. Peter PJ, De Mola CL, De Matos MB, Coelho FM, Pinheiro KA, et al. (2017) Association between perceived social support and anxiety in pregnant adolescents. Revista Brasileira de Psiquiatria 39(1): 21-27.
17. Abedian Z, Soltani N, Mokhber N, Esmaily H (2015) Relationship between social support and postpartum depression in women with preeclampsia. The Iranian Journal of Obstetrics, Gynecology and Infertility 17(136): 10-18.

18. Birgandi SA, Sahaghi H, Jelodari A (2015) The relationship between perceived social support and Academic self-efficacy with social adjustment. Development Strategies in Medical Education 2(1): 26-37.

19. Cheraghi M, Salavati M, Moghimbeigi A (2012) Association between Perceived Social Support and Quality of Life in Patients with heart failure. Iran Journal of Nursing 25(75): 21-31.

20. Sadeghi Aval Shahr H, Moosavi Sahebalzamani S, Jahdi F, Neisani Samani L, Haghani H, et al. (2014) Relationship between perceived social support in first pregnancy with birth satisfaction in primigravid women referred to Shahid Akbar Abadi Hospital. Prev Care Nurs Midwif J 4(1): 54-64.

21. Bodaghi E, Alipour F, Bodaghi M, Nori R, Peiman N, et al. (2017) The Role of Spirituality and Social Support in Pregnant Women's Anxiety, Depression and Stress Symptoms. Community Health Journal 10(2): 7282.

22. Fayazi S, Ghasemi F, Ghobadian M, Zenoozian S, Kharaghani R, et al. (2017) Relationship between social support with anxiety, depression, and stress in pregnant women attending to health care centers in Zanjan-Iran in 2015-2016. Preventive Care in Nursing \& Midwifery Journal 7(2): 41-48.

23. Sherbourne CD, Stewart AL (1991) The MOS social support survey. Social science \& medicine 32(6): 705-714.

24. Tamanayefar MR, laith H, Mansouri Nik h (2017) The Relationship of Perceived Social Support with Student Self-Efficacy. social Psychology 2(28): 31-39.

25. Khatibi N, Ahmadi Koumeleh S, Mamianloo H, Abbasi Abyaneh N (2013) Relationship between Perceived Social Support and Pre/post-operation Anxiety and Depression in Patients undergoing CABG. Iran Journal of Nursing 26(84): 63-70

26. Sahebi A, Asghari MJ, Salari RS (2005) Validation of depression anxiety and stress scale (DASS-21) for an Iranian population. Iranian Psychologists 4(1): 299-313.

27. Lovibond SH, Lovibond PF (1996) Manual for the depression anxiety stress scales: Psychology Foundation of Australia.

28. Faramarzi M, Pasha H (2015) The role of social support in prediction of stress during pregnancy. J Babol Univ Med Sci 17(11): 52-60.

29. Almalki MS, Hakami OAO, Al Amri AM (2017) Assessment of Preoperative Anxiety among Patients Undergoing Elective Surgery. Egyptian Journal of Hospital Medicine 69(4).

30. Rogers HL, Brotherton HT, Plaza SLO, Durán MAS, Altamar MLP, et al. (2015) Depressive and anxiety symptoms and social support are independently associated with diseasespecific quality of life in Colombian patients with rheumatoid arthritis. Revista brasileira de reumatologia 55(5): 406-413

31. Nasseh M, Ghazinour M, Joghataei M, Nojomi M, Richter J, et al. (2011) A persian version of the social support questionnaire (SSQ). Social Welfare Quarterly 11(41): 251-266. 


\section{ISSN: 2574-1241}

DOI: 10.26717/BJSTR.2021.35.005698

Hashemi Zeinab. Biomed J Sci \& Tech Res

(C) (P) This work is licensed under Creative

Submission Link: https://biomedres.us/submit-manuscript.php

$\begin{array}{ll}\text { BIOMEDICAL } & \text { Assets of Publishing with us } \\ \text { RESEARCHES } & \text { - Global archiving of articles } \\ & \text { - Immediate, unrestricted online access } \\ & \text { - Rigorous Peer Review Process } \\ & \text { - Authors Retain Copyrights }\end{array}$

